University of South Carolina

Scholar Commons

$8-2010$

\title{
Modelling and Verification of Response of RC Slabs Strengthened in Flexure with Mechanically Fastened FRP Laminates
}

\author{
Annalisa Napoli \\ Fabio Matta \\ University of South Carolina - Columbia, fmatta@sc.edu \\ Enzo Martinelli \\ Antonio Nanni \\ Roberto Realfonzo
}

Follow this and additional works at: https://scholarcommons.sc.edu/eche_facpub

Part of the Civil Engineering Commons, and the Structural Engineering Commons

\footnotetext{
Publication Info

Published in Magazine of Concrete Research, Volume 62, Issue 8, 2010, pages 593-605.

Napoli, A., Matta F., Martinelli, E., Nanni, A., Realfonzo, R. (2010). Modelling and verification of response of $\mathrm{RC}$ slabs strengthened in flexure with mechanically fastened FRP laminates. Magazine of Concrete Research. 62(8), 593-605.

(c) Magazine of Concrete Research, 2010, Institution of Civil Engineers

http://dx.doi.org/10.1680/macr.2010.62.8.593
}

This Article is brought to you by the Chemical Engineering, Department of at Scholar Commons. It has been accepted for inclusion in Faculty Publications by an authorized administrator of Scholar Commons. For more information, please contact digres@mailbox.sc.edu. 


\section{Modeling and verification of response of RC slabs strengthened in flexure with mechanically fastened FRP laminates}

Article in Magazine of Concrete Research · August 2010

Impact Factor: 0.91 · DOI: 10.1680/macr.2010.62.8.593

CITATIONS

17

5 authors, including:

\section{Annalisa Napoli}

Università degli Studi di Salerno

60 PUBLICATIONS 234 CITATIONS

SEE PROFILE

\section{Antonio Nanni}

University of Miami

390 PUBLICATIONS $\quad 5,168$ CITATIONS

SEE PROFILE
READS

73
Fabio Matta

University of South Carolina

87 PUBLICATIONS 470 CITATIONS

SEE PROFILE

Enzo Martinelli

Università degli Studi di Salerno

134 PUBLICATIONS 830 CITATIONS

SEE PROFILE 


\title{
Modelling and verification of response of RC slabs strengthened in flexure with mechanically fastened FRP laminates
}

\author{
A. Napoli*, F. Matta†, E. Martinelli*, A. Nanni†t and R. Realfonzo*
}

Mechanically fastened fibre-reinforced polymer laminate systems are emerging as a promising means for the repair and strengthening of reinforced concrete members. This technology entails the use of pultruded carbon-and glassvinyl ester fibre-reinforced polymer laminates with enhanced longitudinal bearing strength that are connected to the concrete substrate by means of steel anchors. Attractive applications are those for emergency repairs where constructability and speed of installation are critical requirements. In this paper, an experimental investigation is first presented that included laboratory testing of scaled reinforced concrete slabs strengthened with four different combinations of laminate lengths and fastener layouts to study optimised strengthening configurations. Compelling evidence was gained on the influence of the partial interaction between reinforced concrete slabs and mechanically fastened fibre-reinforced polymer laminates on the flexural response arising predominantly from bearing of the fasteners on to the fibre-reinforced polymer laminate. A numerical study is presented where the proposed finiteelement procedure incorporates non-linear constitutive models for materials and the concrete-fibre-reinforced polymer interface. For the latter, an accurate and simplified, conservative bilinear stress-slip model is successfully implemented and verified to evaluate applicability for analysis and design purposes.

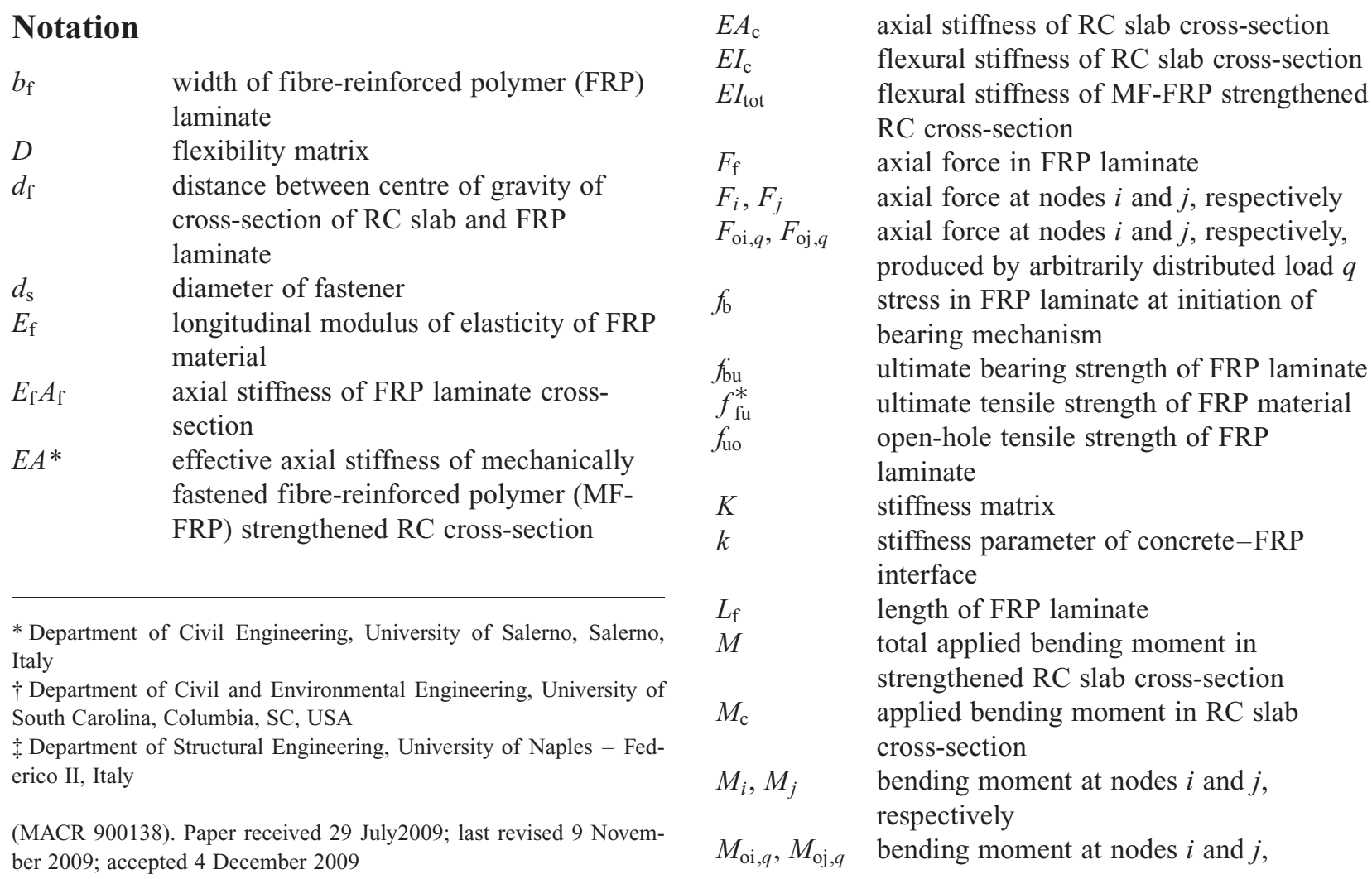


respectively, produced by arbitrarily distributed load $q$

$M_{\mathrm{u}} \quad$ maximum bending moment at failure

$M_{\mathrm{y}} \quad$ maximum bending moment at yielding of steel reinforcement

$N_{\mathrm{b}} \quad$ total number of fasteners along MF-FRP laminate

$P$

$Q$

$Q_{0}$

$q$

$s$

$\boldsymbol{S}$

$s_{\mathrm{b}}$

$s_{\text {bu }}$

$s_{i}, s_{j}$

$t_{\mathrm{f}}$

$u_{\mathrm{c}}$

$u_{\mathrm{c}, \mathrm{i}}$

$u_{\mathrm{f}}$

$u_{\mathrm{f}, \mathrm{i}}$

$V_{i}, V_{j}$

$V_{\text {oi }, q}, V_{\text {oj }, q}$

$v_{i}, v_{j}$

X

$y_{\mathrm{c}, \mathrm{i}}$

$y_{\mathrm{NA}}$

$\Delta M_{\mathrm{u}}$

$\Delta M_{\mathrm{y}}$

$\Delta \delta_{\mathrm{u}}$

$\Delta \delta_{\mathrm{y}}$

$\delta$

$\delta_{\mathrm{u}}$

$\delta_{\mathrm{y}}$

$\varepsilon_{\mathrm{c}}$

$\varepsilon_{\mathrm{cu}}$

\begin{tabular}{|c|c|}
\hline$\varepsilon_{\mathrm{f}}$ & longitudinal strain in FRP laminate \\
\hline$\varepsilon_{\mathrm{fu}}^{*}$ & ultimate tensile strain of FRP material \\
\hline$\varepsilon_{\mathrm{s}}$ & longitudinal strain in steel bar \\
\hline$\sigma_{f}$ & $\begin{array}{l}\text { bearing stress produced by the fastener in } \\
\text { FRP laminate }\end{array}$ \\
\hline$\phi$ & $\begin{array}{l}\text { rotation of strengthened RC slab cross- } \\
\text { section on } y-z \text { plane }\end{array}$ \\
\hline $\begin{array}{l}\phi_{i}, \phi_{j} \\
\chi\end{array}$ & $\begin{array}{l}\text { end rotation at nodes } i \text { and } j \text {, respectively } \\
\text { curvature of RC slab cross-section }\end{array}$ \\
\hline
\end{tabular}

\section{Introduction}

The use of mechanically fastened (MF) fibre-reinforced polymer (FRP) laminates is emerging as a viable approach for the flexural strengthening of reinforced concrete (RC) members (Lamanna, 2002; Lamanna et al., 2001, 2004a). This technology relies on pre-cured FRP laminates with enhanced bearing strength that are connected to the concrete substrate by means of steel anchors, which makes the material well suited for emergency repairs where constructability and speed of installation are critical requirements. In fact, unlike externally bonded (EB) FRP laminates (ACI, 2008; Teng et al., 2002) and near-surface-mounted (NSM) bars (De Lorenzis and Teng, 2007), MF-FRP systems require minimal surface preparation, no special tools and no trained personnel for installation; this enables their immediate use on the strengthened structure.

Significant research has been conducted to study the structural response of mechanical connections between FRP laminates and steel fasteners, either screw-type or installed using a powder-actuated gun (Elsayed et al., 2009; Lamanna, 2002; Rizzo, 2005). Experimental evidence was also gained from strengthened RC beams with rectangular cross-sections (Lamanna et al., 2001, 2004a; Martin and Lamanna, 2008) and tee crosssections (Lamanna et al., 2004b), where fasteners were mounted using different layouts to evaluate their efficiency. Comparative experimental studies (Ekenel et al., 2006; Quattlebaum et al., 2005) on the static and fatigue performance of RC beams strengthened with MF- and EB-FRP laminates, as well as NSM FRP strips, showed that similar strength levels can be attained.

The MF-FRP technology has been transferred into a number of field implementation projects on civil and military RC bridge structures (Arora, 2003; Bank et al., 2003; Rizzo, 2005). There appears to be some interest also in applications on timber structures (Dempsey and Scott, 2006), while the use for emergency repair of masonry (also historical) structures holds significant potential, and draws an additional benefit from the enhanced reversibility attained with MF-FRP systems (Ascione et al., 2009).

Simplified analytical models to predict the flexural response of MF-FRP strengthened RC members have been proposed (Bank and Arora, 2007; Lamanna, 2002) that rely on the assumption of conservation of plane

Magazine of Concrete Research, 2010, 62, No. 8 
sections, thereby neglecting the relative displacement (slip) between the concrete substrate and the FRP laminate as it occurs due to the bearing of the mechanical fasteners on to the laminate. This paper presents an experimental and numerical investigation aimed at advancing the knowledge of the behaviour of RC members strengthened in flexure with MF-FRP laminates. First, an experimental programme is reported where compelling evidence was gained on the partial interaction between RC slabs and MF-FRP laminates arising from bearing of the fasteners on to the laminate. The effects on strength increase and failure mode of fastener layout, FRP laminate length, and bearing slip between concrete substrate and FRP laminate are discussed. Then, a numerical study follows with the objective of developing and verifying an accurate model for analysis, from which a simplified and physically meaningful model for design is also derived. The numerical procedure implements an iterative secant algorithm based on a general approach (Faella et al., 2002), previously adapted for the analysis of EB-FRP strengthened beams (Faella et al., 2008), which assumes nonlinear stress-strain constitutive models for concrete, steel and the concrete-FRP interface. The proposed procedure yields strength and maximum deflection predictions that are in good agreement with the experimental measurements, while more conservative results are obtained using a simplified (bilinear) model to account for interfacial slip, where the plastic plateau initiates on reaching the bearing strength of the MFFRP laminate.

\section{Experimental investigation}

A total of six one-way RC slabs were tested under four-point bending. Four slabs were strengthened with a MF-FRP laminate, a counterpart was strengthened with an EB-FRP laminate, while an unstrengthened slab was used as the control specimen.

\section{Test specimens and materials}

The test specimens were $3658 \mathrm{~mm}$ long and had a cross-section of 305 by $152 \mathrm{~mm}$, as illustrated in Figure 1. The clear span and shear span were 3048 and $1219 \mathrm{~mm}$, respectively. The flexural reinforcement consisted of three No. 4 steel bars $(12.7 \mathrm{~mm}$ diameter $)$, resulting in a longitudinal reinforcing ratio of $0.98 \%$. The slabs were designed to fail in flexure by yielding

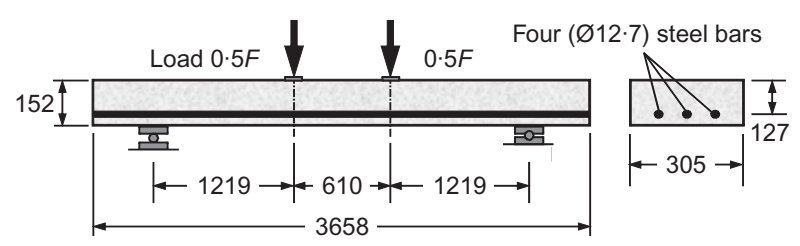

Figure 1. RC slab specimen and test configuration (dimensions in $\mathrm{mm}$ ) of the steel reinforcement, followed by concrete crushing in the case of the strengthened slabs.

Type I Portland cement concrete was used with average cylinder compressive strength and standard deviation of $26.7 \mathrm{MPa}$ and $1.8 \mathrm{MPa}$, respectively, as determined experimentally according to ASTM C39 (ASTM, 2009). Grade 60 steel bars with yield strength of $414 \mathrm{MPa}$ were used as flexural reinforcement. The pre-cured laminates shown in Figure 2(a) used for the MF-FRP system were glass- and carbon-vinyl ester pultruded strips with enhanced transverse and bearing strength by means of embedded fibreglass mats (Strongwell, 2009). Width and thickness of the laminates were 102 and $3.2 \mathrm{~mm}$, respectively. Wedge-bolt screw anchors (Powers Fasteners, 2008) made of zincplated carbon steel were used as fasteners (Figure 2(b)). The anchors had a $44.5 \mathrm{~mm}$ shank length and a $9.5 \mathrm{~mm}$ diameter, and were driven into pre-dilled holes using a common torque wrench. In order to investigate the feasibility of the easiest and most practical MF-FRP installation, neither washers nor gap fillers (resin) were used. A unidirectional carbon fibre sheet with ply

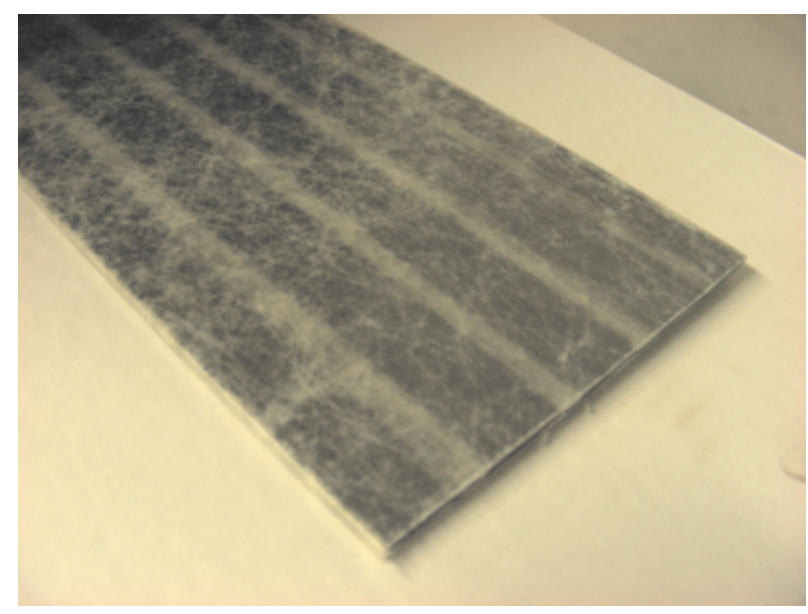

(a)

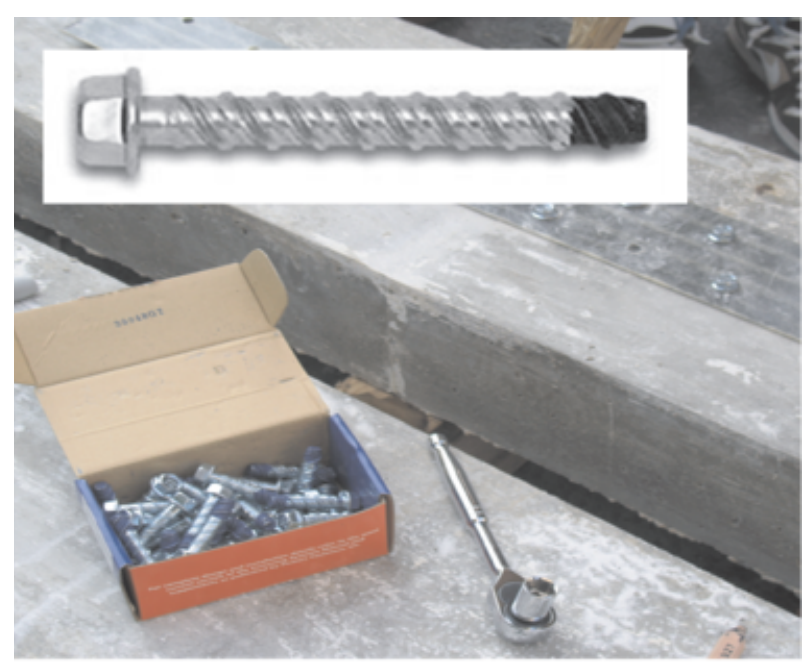

(b)

Figure 2. MF-FRP strengthening system: (a) laminate; (b) wedge-bolt screw anchors 
$0.165 \mathrm{~mm}$ thick and $305 \mathrm{~mm}$ wide was used for the EB-FRP counterpart, and installed by way of wet layup with a two-part epoxy saturant (BASF, 2008). Relevant mechanical properties of the linear-elastic FRP strengthening materials are reported in Table 1, where $f_{\mathrm{fu}}, E_{\mathrm{f}}$ and $\varepsilon_{\mathrm{fu}}$ are the FRP tensile strength, elastic modulus and ultimate strain, respectively. In the case of the EB-FRP system, the properties are those of the reinforcing fibres. In the case of the MF-FRP system, the properties are those of the pre-cured FRP laminate, where $f_{\text {uo }}$ and $f_{\text {bu }}$ denote the open-hole tensile strength and the ultimate bearing strength, respectively (Elsayed et al., 2009).

\section{MF-FRP strengthening layout and test matrix}

The spacing and pattern of the fasteners play a key role in the response of an MF-FRP system. Failure of the FRP laminate may accrue from net-tension, cleavage-tension, bearing, and shear-out mechanisms (Camanho and Matthews, 1997; Hassan et al., 1997a, 1997b), where bearing is the most desirable failure mode since the connection reaches its strength while allowing significant deformations (Lamanna, 2002; Rizzo, 2005), whereas the other failure modes develop in a more brittle fashion (Rosner and Rizkalla, 1995). Pry-out or spalling of the concrete may also lead to failure of an MF-FRP strengthening system, typically accruing from the interaction of the stress fields produced in the concrete around closely spaced fasteners (Lamanna, 2002; Rizzo, 2005).

Two fastener layouts are used in this study as shown in Figure 3: pattern No. 1, where the number of fasteners is equal to the numbers of pre-drilled holes; and pattern No. 2, where the fasteners are placed at every second hole. In each configuration, the FRP laminate has two staggered rows of holes, which allow for an optimal use of the laminate strength by minimising shear lag effects that occur when using a single row of fasteners (Rizzo, 2005), while staggering of the rows allows for a more even longitudinal stress distribution (Martin and Lamanna, 2008). The fastener on-centre spacing of $76 \mathrm{~mm}$ was selected to prevent the occurrence of premature failure due to laminate shear-out or concrete pry-out (Rizzo, 2005; Martin and Lamanna, 2008). The edge distance of $64 \mathrm{~mm}$ was selected to offset the likelihood of laminate cleavage-tension failure (Lamanna, 2002), and to prevent shear-out failure at the outermost fasteners (Rizzo, 2005).

For each test specimen, Table 2 reports laminate

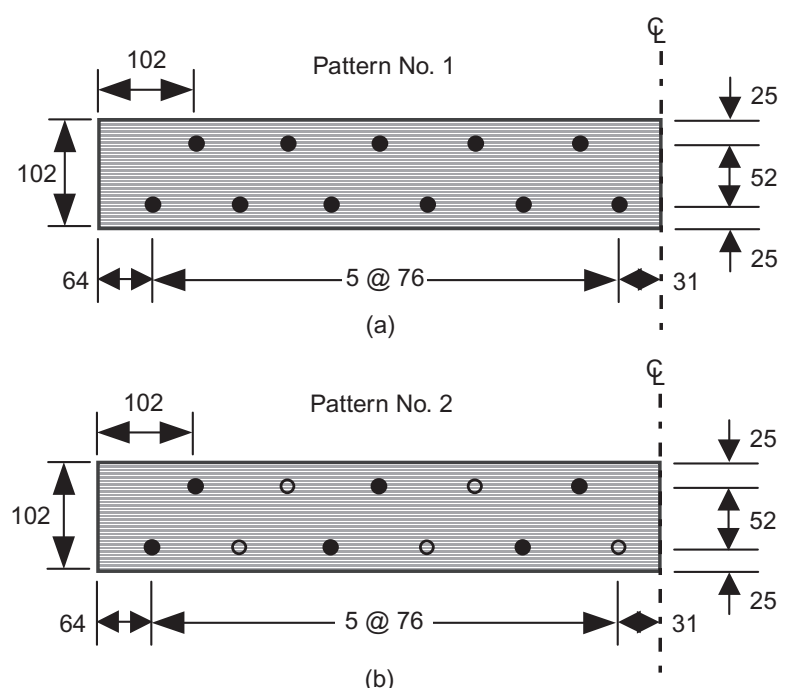

Figure 3. Fastener layout: (a) pattern No. 1; (b) pattern No. 2 (dimensions in $\mathrm{mm}$ )

Table 2. Configuration of FRP strengthening systems

\begin{tabular}{l|c|c|c|c|c}
\hline Test & $b_{\mathrm{f}}: \mathrm{mm}$ & $t_{\mathrm{f}}: \mathrm{mm}$ & $L_{\mathrm{f}}: \mathrm{mm}$ & Pattern No. & $N_{\mathrm{b}}$ \\
\hline C & - & - & - & - & - \\
EB & 305 & $0 \cdot 165^{*}$ & 2865 & - & - \\
MF-1-L & 102 & $3 \cdot 2$ & 2718 & 1 & 67 \\
MF-1-S & 102 & $3 \cdot 2$ & 2108 & 1 & 51 \\
MF-2-L & 102 & $3 \cdot 2$ & 2718 & 2 & 35 \\
MF-2-S & 102 & $3 \cdot 2$ & 2413 & 2 & 29 \\
\hline
\end{tabular}

* Nominal ply thickness.

width, $b_{\mathrm{f}}$, thickness, $t_{\mathrm{f}}$, and length, $L_{\mathrm{f}}$. Fastener layout (either pattern No. 1 or No. 2) and total number of fasteners, $N_{\mathrm{b}}$, are also provided for the MF-FRP strengthened slabs. The control specimen and the EBFRP strengthened specimen are denoted as ' $\mathrm{C}$ ' and 'EB', respectively. The MF-FRP strengthened specimens are labelled as 'MF-X-Y', where $\mathrm{X}$ indicates the fastener layout (' 1 ' for pattern No. 1, '2' for pattern No. 2), and $Y$ indicates the laminate length (' $\mathrm{L}$ ' for longer laminate, ' $S$ ' for shorter laminate). All the strengthened slabs were preliminarily designed to achieve a similar nominal flexural strength (Napoli, 2008) based on an existing simplified analytical procedure (Bank and Arora, 2007). The length of the FRP laminate in specimens MF-1-S and MF-2-S was selected as the minimum to attain the target nominal strength (Napoli, 2008).

Table 1. Mechanical properties of FRP materials and fasteners

\begin{tabular}{l|c|c|c|c|c}
\hline Strengthening & $f_{\mathrm{fu}}^{*}: \mathrm{MPa}$ & $E_{\mathrm{f}}: \mathrm{GPa}$ & $\varepsilon_{\mathrm{fu}}^{*}: \%$ & $f_{\mathrm{uo}}: \mathrm{MPa}$ & $f_{\mathrm{bu}}: \mathrm{MPa}$ \\
\hline EB-FRP & 3800 & 227 & $1 \cdot 67$ & - & - \\
MF-FRP & 852 & 62 & $1 \cdot 36$ & 652 & 385 \\
\hline
\end{tabular}

Allowable fastener capacity (safety factor: 4): $3 \cdot 0 \mathrm{kN}$ (tension); $5 \cdot 5 \mathrm{kN}$ (shear) 


\section{Test set-up and instrumentation}

The specimens were tested in four-point bending according to the schematic diagram shown in Figure 1. Direct current voltage transformer (DCVT) sensors were used to measure vertical displacement at mid-span and settlement at the supports. Several strain gauges were used to measure compression strain in the concrete and tensile strain in the steel reinforcement at mid-span, as well as longitudinal strain in the FRP laminate.

\section{Experimental results and discussion}

\section{Strength and failure mode}

The failure mode and crack pattern of all specimens are illustrated in the photographs of Figures 4 and 5 . The control specimen, $\mathrm{C}$, failed in flexure by yielding of the steel reinforcement, followed by crushing of the concrete at mid-span, at a maximum load of $23.5 \mathrm{kN}$, as shown in Figure 4(a).

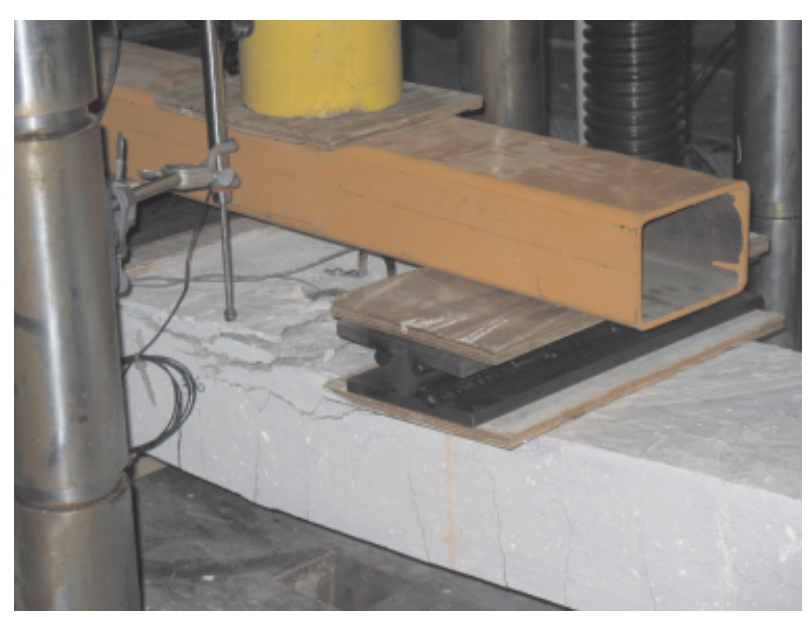

(a)

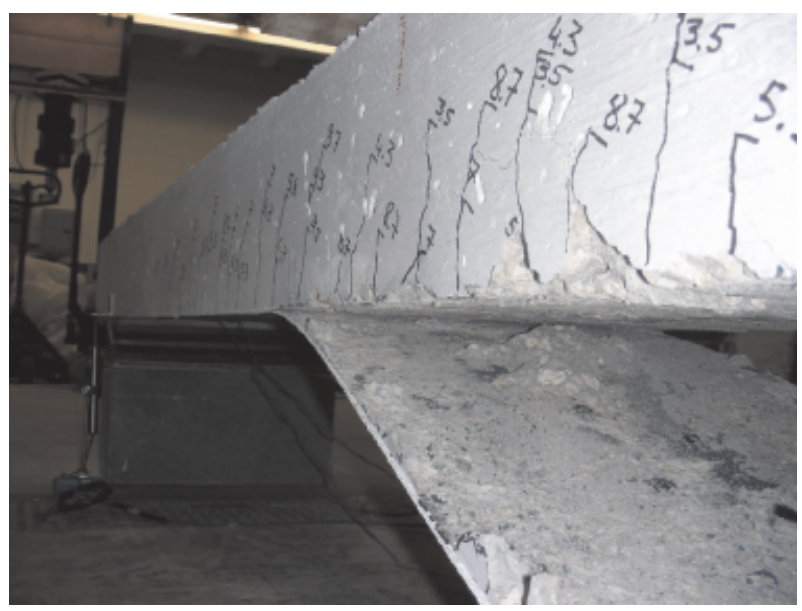

(b)

Figure 4. Photographs of failed specimens: (a) specimen $C$; (b) specimen $E B$
The EB-FRP specimen, EB, failed by yielding of the steel reinforcement followed by debonding of the FRP laminate at a maximum load of $34.5 \mathrm{kN}$, as shown in Figure 4(b). The maximum concrete strain at mid-span was $2248 \mu \varepsilon$. While a $48.5 \%$ strength increase was attained, the fact that failure was not governed by crushing of the concrete, as expected, and that the concrete cover did not delaminate, indicates that the installation may have been flawed, and emphasises the sensitivity of EB-FRP systems to the adhesive bonding procedure.

All of the MF-FRP strengthened slabs failed by yielding of the steel reinforcement followed by crushing of the concrete at either the mid-span section (MF-1-L) or a loading section (MF-1-S, MF-2-L and MF-2-S), as documented in Figure 5. A significant distribution of flexural cracks was observed along the members early after the cracking moment was attained, most likely due to local damage of the concrete substrate induced when the fasteners were installed, with no apparent effect on the overall flexural stiffness. Detachment of the FRP laminate from the concrete surface never occurred, while the observed failure modes highlight that the selection of fastener layouts (pattern No. 1 or No. 2) was effective in preventing brittle failure mechanisms, as no shear-out and cleavage failure in the FRP laminate or pry-out failure at the mechanical connections occurred. Figure 6 shows the maximum applied moment-mid-span displacement curves for all test specimens.

The pre-yielding behaviour of all FRP-strengthened specimens is fairly similar. Past yielding of the steel reinforcement, the FRP laminate is fully engaged. Specimens MF-1-L and MF-1-S exhibited a similar response to specimen EB in terms of post-yielding stiffness and strength, with a slight increase in strength for specimen MF-1-L. Conversely, while specimens MF-2-L and MF-2-S reached a strength comparable with that of specimen EB, a smaller and post-yielding stiffness was observed that was accompanied by larger maximum displacements at similar levels of applied bending moment. This behaviour is attributed to the fact that there are a smaller number of fasteners per unit length in pattern No. 2, resulting in a greater shear force per fastener at the same load level compared with pattern No. 1; this allowed the development of a bearing-slip mechanism that produced greater deformation than in the case of pattern No. 1. This hypothesis is corroborated by observation of the damage level in the FRP laminate at the fastener holes for specimens MF1-S and MF-2-S, as shown in Figure 7, where the larger local deformations due to bearing are evident in the latter case.

Table 3 reports relevant test results, including: maximum moment and mid-span displacement at yielding of the steel reinforcement $\left(M_{\mathrm{y}}, \delta_{\mathrm{y}}\right)$ and at ultimate $\left(M_{\mathrm{u}}\right.$, $\delta_{\mathrm{u}}$ ); and percentage variation of flexural strength and mid-span deflection with respect to the control speci- 


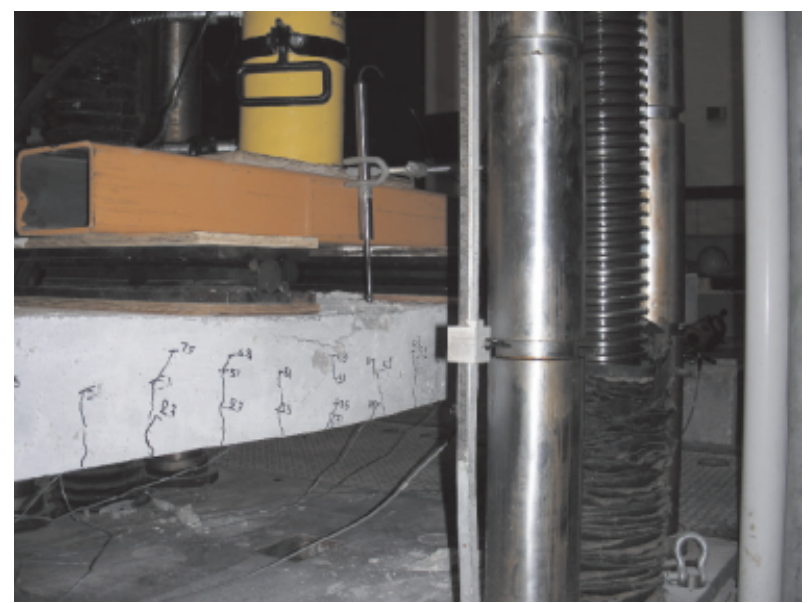

(a)

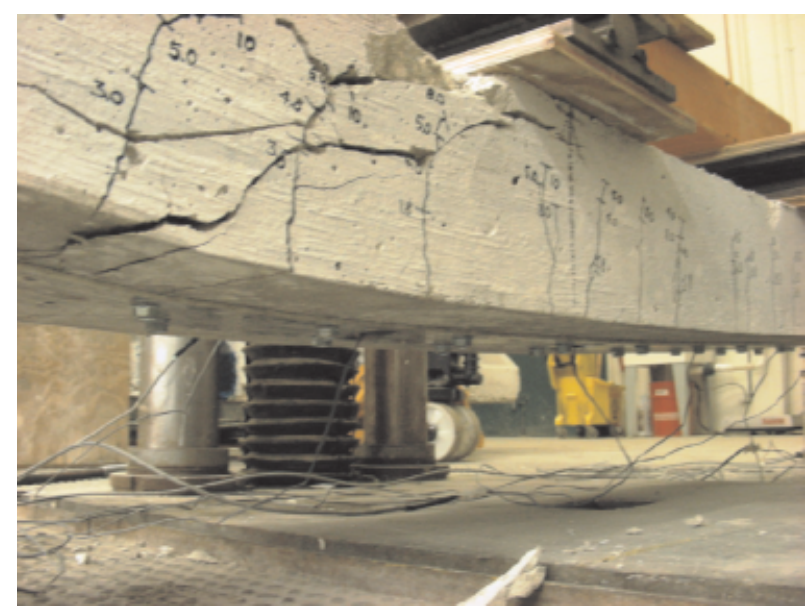

(c)

Figure 5. Photographs of failed MF-FRP strengthened specimens:

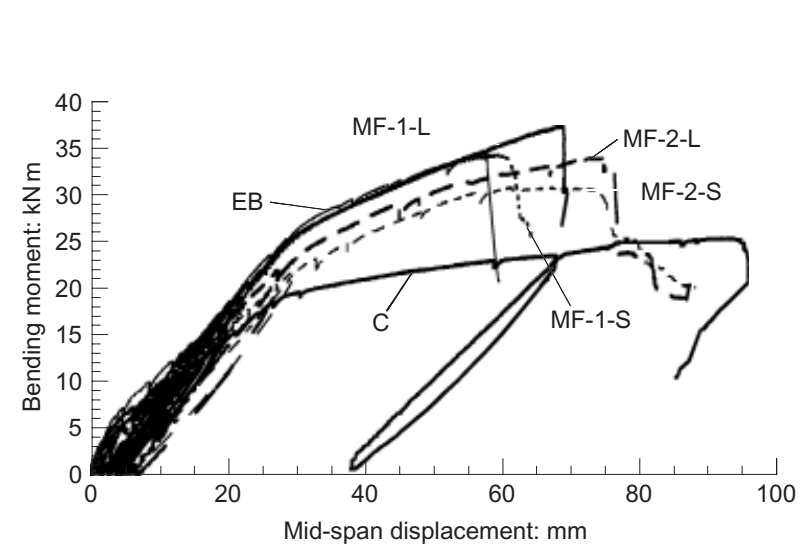

Figure 6. Maximum bending moment-mid-span displacement plot for all specimens

men, $\mathrm{C}$, at yielding of the steel reinforcement $\left(\Delta \delta_{\mathrm{y}}\right.$, $\left.\Delta M_{\mathrm{y}}\right)$ and at ultimate $\left(\Delta \delta_{\mathrm{u}}, \Delta M_{\mathrm{u}}\right)$. The values of $M_{\mathrm{y}}$ and of the associated displacement $\delta_{\mathrm{y}}$ are defined as the level at which the strain in the steel reinforcement reached a measured value of $2000 \mu \varepsilon$. The values of $M_{\mathrm{u}}$ and of the associated displacement $\delta_{\mathrm{u}}$ are defined as the level at which the maximum load was reached. The following conclusions are drawn.

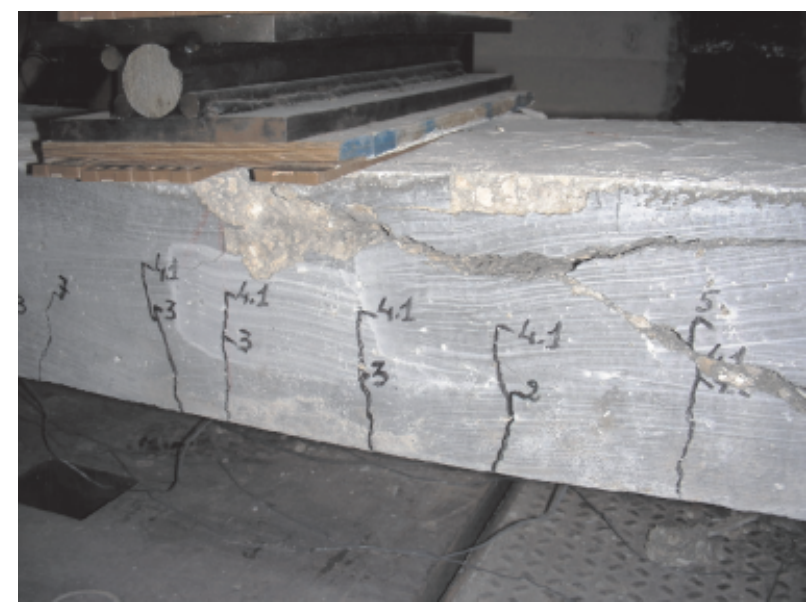

(b)

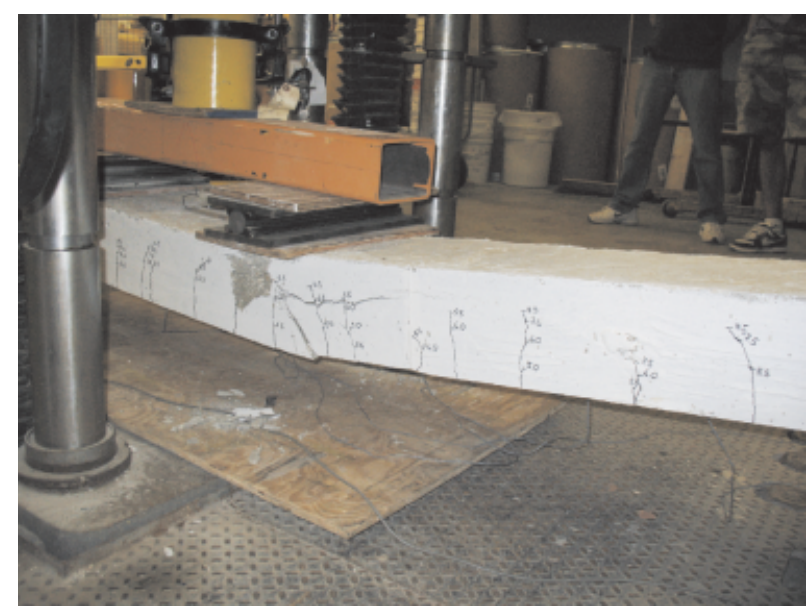

(d)

(a) $M F-1-L$; (b) $M F-1-S$; (c) $M F-2-L$; (d) $M F-2-S$

(a) At yielding of the steel reinforcement, the slabs strengthened with MF-FRP laminates exhibited increases in the yield moment with respect to the control specimen ranging from $12.9 \%$ (MF-2-L) to $26.6 \%$ (MF-1-S); the maximum decrease in midspan displacement was limited to $1 \cdot 7 \%$ (MF-1-L).

(b) At ultimate, the slabs strengthened with MF-FRP laminates exhibited increases in ultimate moment ranging from $31 \cdot 1 \%(\mathrm{MF}-2-\mathrm{S})$ to $58 \cdot 7 \%(\mathrm{MF}-1-\mathrm{L})$, along with a reduction in mid-span displacement. Such reduction was greater for the specimens that used pattern No. 1 in Figure 3(a).

(c) The strength increase for the MF-FRP specimens is comparable to that attained using the EB-FRP strengthening system.

(d) The deformability with respect to specimen EB is enhanced using MF-FRP laminates with the fasteners arranged per pattern No. 2, despite a smaller ultimate strength compared to the counterparts that used pattern No. 1. In fact, prior to crushing of the concrete, the smaller number of fasteners per unit length in pattern No. 2 enabled a more efficient use of the FRP laminate by triggering the bearing-

Magazine of Concrete Research, 2010, 62, No. 8 


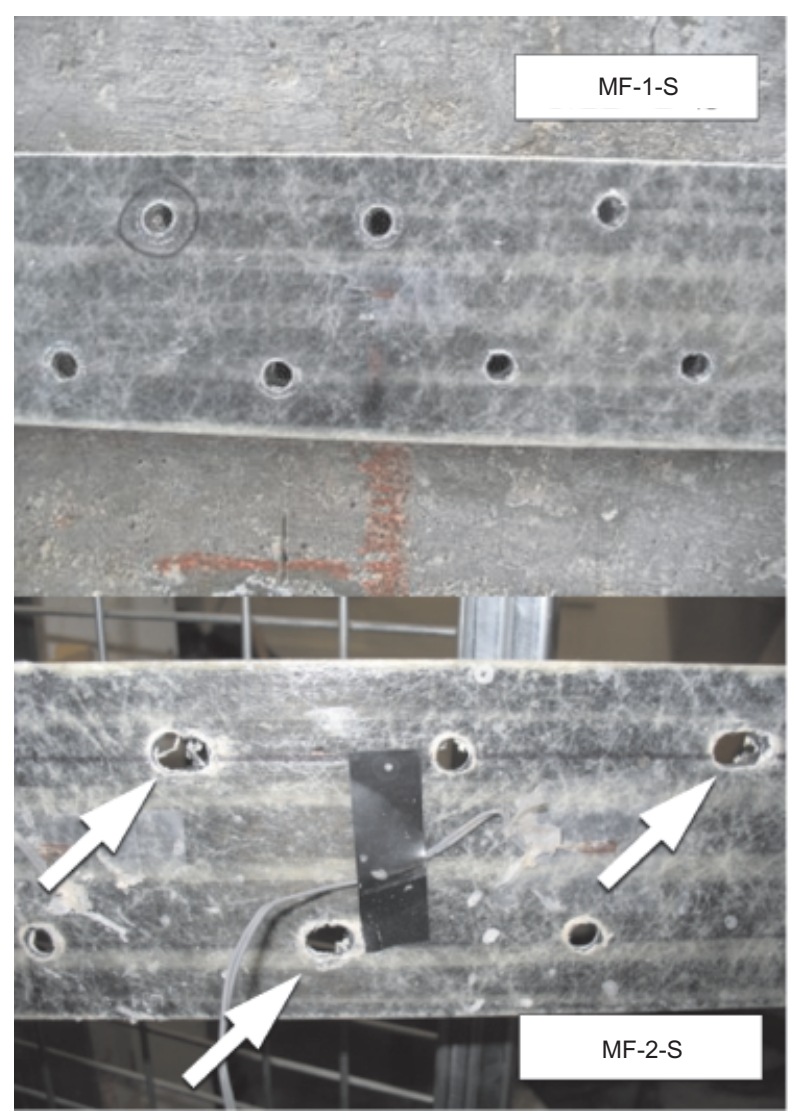

Figure 7. Bearing damage in FRP laminate on MF-FRP specimens: $M F-1-S$ (top) and $M F-2-S$ (bottom)

slip mechanism that produces greater deformability than pattern No. 1.

\section{Longitudinal strain in FRP laminate}

Representative longitudinal strain profiles along the FRP laminate at increasing values of maximum bending moment are shown in Figure 8. A highly non-linear strain distribution is observed in specimen EB as the laminate debonding mechanism develops, starting from the formation of the critical flexural-shear cracks outwards from the closer loading section. Irrespective of the load level, a fairly linear and symmetric strain distribution is observed in the MF-FRP strengthened specimens. This is true also past yielding of the steel

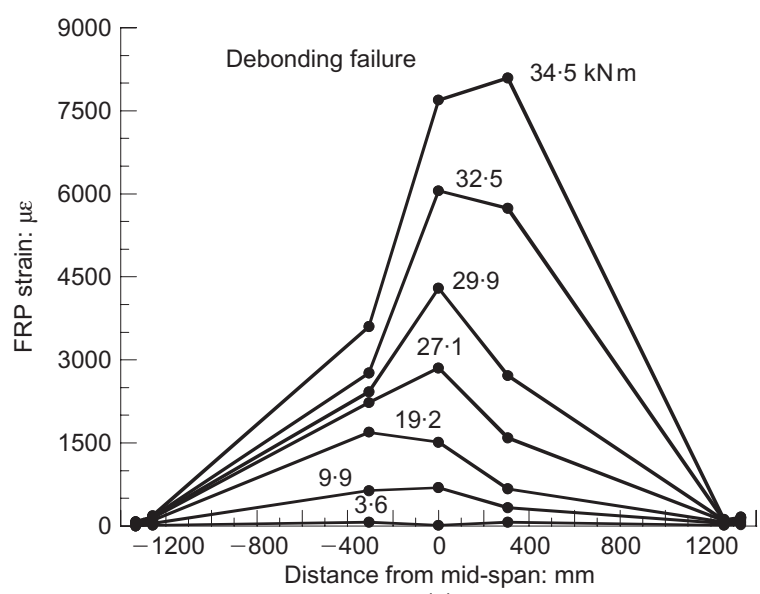

(a)
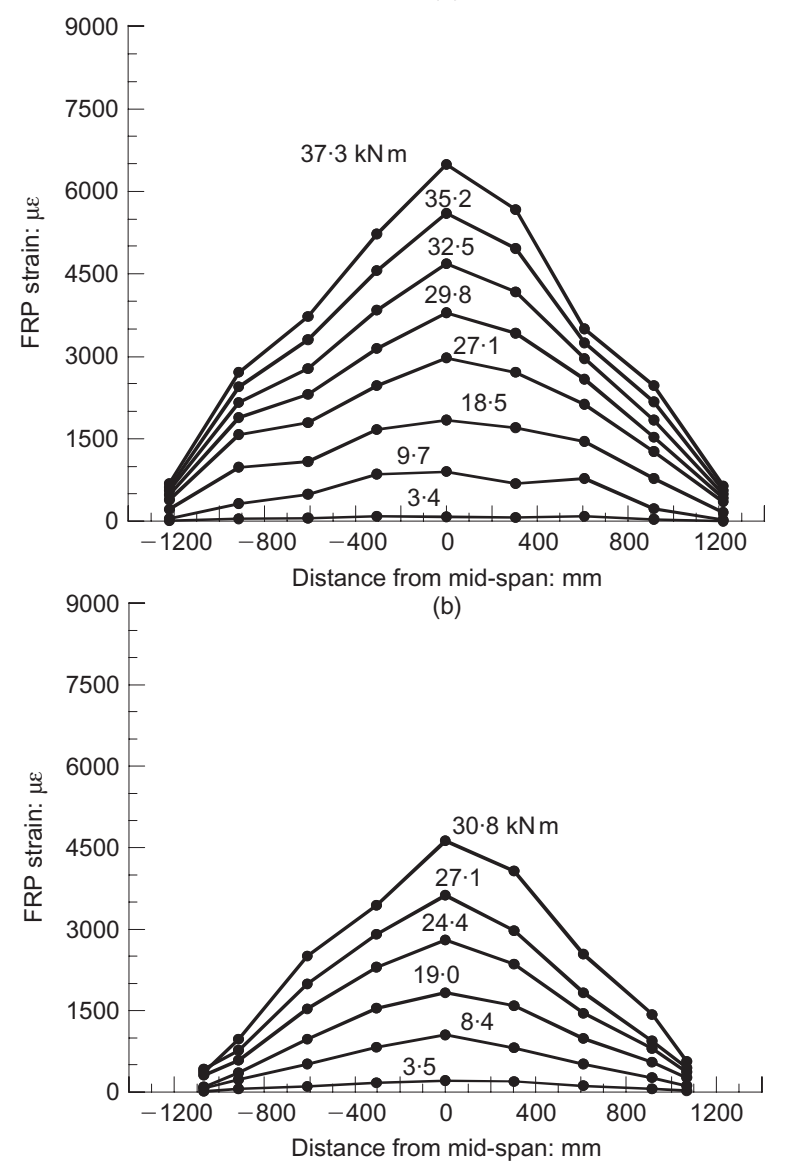

(c)

Figure 8. Longitudinal strain profile along FRP laminate at increasing maximum bending moment in representative specimens: (a) EB; (b) $M F-1-L$; (c) $M F-2-S$

Table 3. Experimental test results

\begin{tabular}{l|c|c|c|c|c|c|c|c}
\hline Specimen ID & $M_{\mathrm{y}}: \mathrm{kN} \mathrm{m}$ & $\Delta M_{\mathrm{y}}: \%$ & $\delta_{\mathrm{y}}: \mathrm{mm}$ & $\Delta \delta_{\mathrm{y}}: \%$ & $M_{\mathrm{u}}: \mathrm{kN} \mathrm{m}$ & $\Delta M_{\mathrm{u}}: \%$ & $\delta_{\mathrm{u}}: \mathrm{mm}$ & $\Delta \delta_{\mathrm{u}}: \%$ \\
\hline C & $14 \cdot 3$ & - & $19 \cdot 6$ & - & $23 \cdot 5$ & - & $91 \cdot 4$ & - \\
EB & $18 \cdot 7$ & $30 \cdot 7$ & $20 \cdot 7$ & $5 \cdot 4$ & $34 \cdot 5$ & $46 \cdot 8$ & $58 \cdot 4$ & $-36 \cdot 1$ \\
MF-1-L & $17 \cdot 5$ & $22 \cdot 3$ & $19 \cdot 3$ & $-1 \cdot 7$ & $37 \cdot 3$ & $58 \cdot 7$ & $68 \cdot 6$ & $-25 \cdot 0$ \\
MF-1-S & $18 \cdot 1$ & $26 \cdot 6$ & $20 \cdot 6$ & $4 \cdot 9$ & $34 \cdot 3$ & $46 \cdot 0$ & $58 \cdot 4$ & $-36 \cdot 1$ \\
MF-2-L & $16 \cdot 2$ & $12 \cdot 9$ & $19 \cdot 6$ & $-0 \cdot 1$ & $33 \cdot 9$ & $44 \cdot 3$ & $73 \cdot 7$ & $-19 \cdot 4$ \\
MF-2-S & $16 \cdot 3$ & $13 \cdot 5$ & $20 \cdot 7$ & $5 \cdot 7$ & $30 \cdot 8$ & $31 \cdot 1$ & $66 \cdot 0$ & $-27 \cdot 8$ \\
\hline
\end{tabular}


reinforcement, which indicates that the load is transferred evenly among the fasteners along the shear spans, while the measured peak strain at similar load levels is clearly greater when using pattern No. 2 (MF2-S) compared to pattern No. 1 (MF-1-L), consistently with the hypothesis of development of the bearing-slip mechanism discussed in the previous section.

\section{Bearing-slip at concrete-FRP interface}

Figure 9 illustrates the position of the neutral axis at mid-span at increasing loads for a representative specimen (MF-1-L), under the assumption of conservation of plane sections. The position of the neutral axis was determined by assuming a linear strain distribution throughout the cross-section between the extreme concrete fibre in compression, $\varepsilon_{\mathrm{c}}$, and the steel reinforcement, $\varepsilon_{\mathrm{s}}$. As the ultimate moment was attained $\left(M_{\mathrm{u}}=37 \cdot 3 \mathrm{kN} \mathrm{m}\right)$, the measured strains were $\varepsilon_{\mathrm{c}}=3310 \mu \varepsilon$ and $\varepsilon_{\mathrm{s}}=10865 \mu \varepsilon$, which are associated to a neutral axis depth $y_{\mathrm{NA}}=30 \mathrm{~mm}$. Such value was in agreement with the measured uncracked concrete depth. The strain measured in the extreme FRP fibre in tension, $\varepsilon_{\mathrm{f}}=6495 \mu \varepsilon$, clearly indicates that the strain profile is non-linear and is determined by significant differential deformations ('slip') at the concrete-FRP interface, which initiated at the early loading stages and significantly increased as testing proceeded.

Different components may contribute to the slip mechanism, including: gaps between fasteners and surrounding concrete and, to a larger extent, between fasteners and FRP laminate; elastic deformation of the fasteners under shear forces; and bearing mechanism at the hole locations in the FRP laminate. These phenomena initiate at different loading stages, and their relative influence changes throughout the loading process: for example, bearing of the fasteners on to the FRP laminate

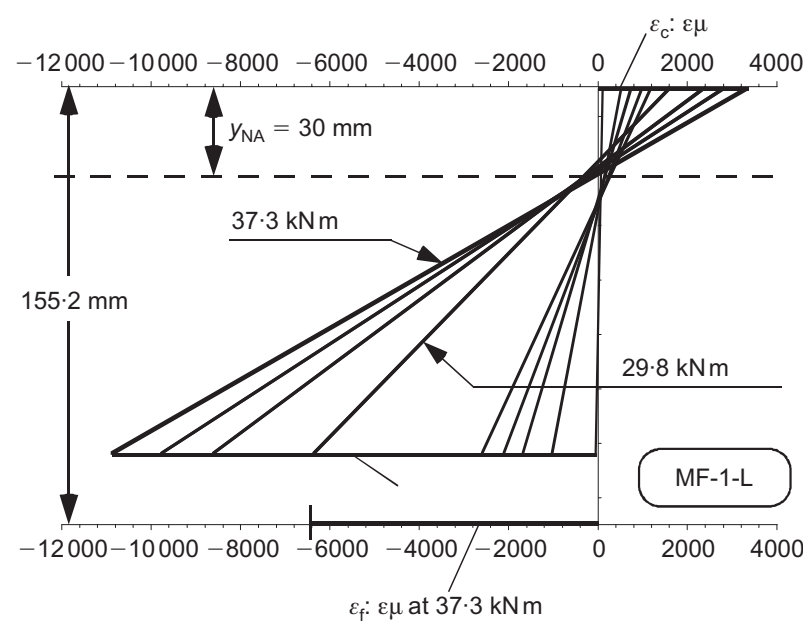

Figure 9. Position of neutral axis at mid-span at increasing maximum bending moment in representative specimen (MF-1-L) under plane-section approximation, computed from strain measured in concrete and steel bars necessarily initiates after the gaps between fasteners and surrounding FRP are filled, and reasonably becomes predominant past yielding of the steel reinforcement. The experimental evidence gained shows that the bearing-slip occurring at the FRP-concrete interface cannot be neglected in the analysis and design of MF-FRP strengthened members at both service and ultimate load conditions, whereby the assumption of conservation of plane sections may lead to inaccurate predictions. In fact, based on this assumption, the maximum longitudinal strain in the FRP in specimen MF-1-L should be comparable with that in the steel reinforcement, whereas the measured values indicate that the former is about $40 \%$ smaller than the latter.

\section{Numerical investigation}

The numerical model used for simulating the behaviour of RC beams externally strengthened with MF-FRP laminates is based on a general algorithm formulated by implementing the differential equation of the wellknown Newmark's theory for steel-concrete composite beams with linear-elastic shear connectors (Newmark et al., 1951) into the 'exact' finite element developed for the analysis of partial interaction in composite beams with flexible shear connectors (Faella et al., 2002). The fundamentals of this approach and the basic assumptions made to implement the numerical procedure are reported in the following subsections.

\section{Newmark's formulation for interaction with elastic shear connectors}

The following assumptions are introduced to model RC beam, MF-FRP laminate and concrete-FRP interface in the linear-elastic range.

(a) The flexural stiffness of the FRP laminate is neglected, and only its axial stiffness is considered.

(b) The interaction between RC beam and MF-FRP laminate is modelled as a continuous, linear medium of negligible thickness.

(c) Equal vertical displacements occur in the connected RC slab and FRP laminate elements.

(d) Shear deformations of the RC slab are neglected.

Relative displacements (slips), $s$, are produced at the concrete-FRP interface owing to the partial interaction between RC slab and FRP laminate, as illustrated in Figure 10, where

$$
\begin{aligned}
s & =u_{\mathrm{c}, \mathrm{i}}-u_{\mathrm{f}, \mathrm{i}}=\left(u_{\mathrm{c}}+\phi y_{\mathrm{c}, \mathrm{i}}\right)-\left(u_{\mathrm{f}}-\phi \frac{t_{\mathrm{f}}}{2}\right) \\
& =u_{\mathrm{c}}-u_{\mathrm{f}}+\phi d_{\mathrm{f}}
\end{aligned}
$$

The axial forces acting on the RC slab and the FRP laminate, applied at the centre of gravity of slab and laminate section, indicated with $G_{\mathrm{c}}$ and $\mathrm{G}_{\mathrm{f}}$, respectively, are denoted with $F_{\mathrm{c}}$ and $F_{\mathrm{f}}$, respectively. The

Magazine of Concrete Research, 2010, 62, No. 8 

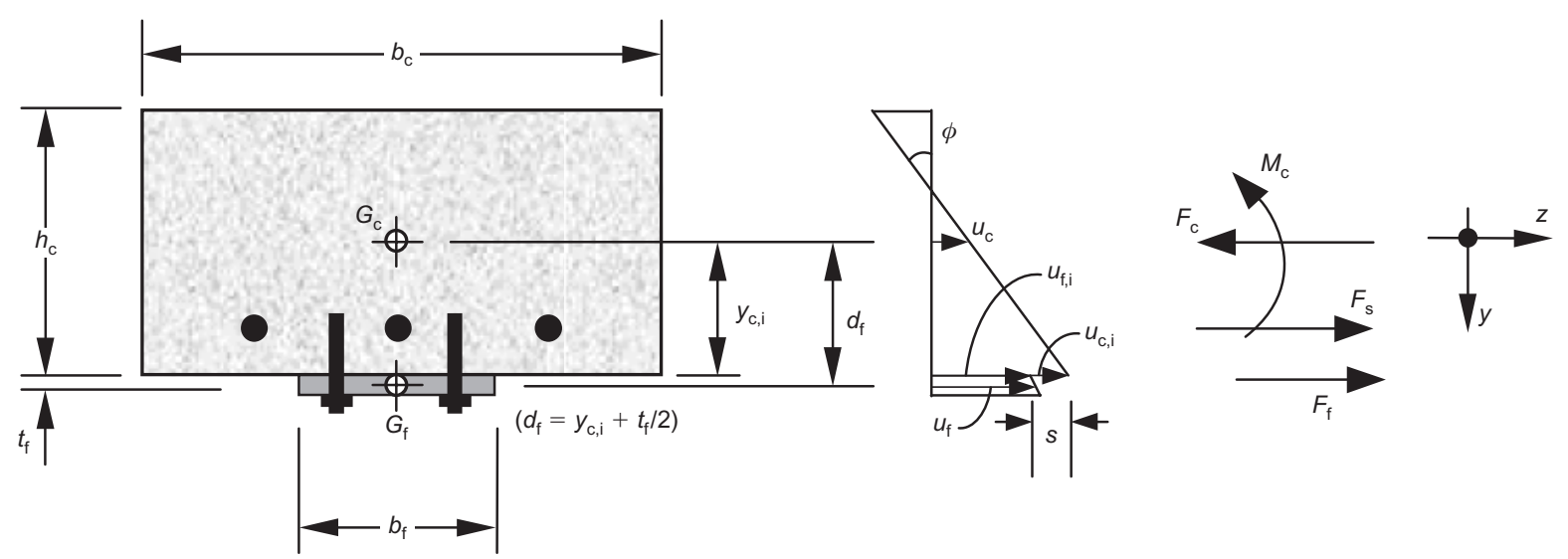

Figure 10. Schematic diagram of internal forces and deformations in cross-section of MF-FRP strengthened RC slab

applied bending moment $M$ at a given cross-section can be expressed as

$$
M=M_{\mathrm{c}}+F_{\mathrm{f}} d_{\mathrm{f}}=\chi E I_{\mathrm{c}}+F_{\mathrm{f}} d_{\mathrm{f}}
$$

where $M_{\mathrm{c}}$ is the bending moment in the $\mathrm{RC}$ slab, $\chi$ is the associated section curvature, and $E I_{\mathrm{c}}$ is the flexural stiffness of the cross-section of the slab. The longitudinal shear force per unit length at the concrete-FRP interface is rendered as a function of the slip $s$ in the following form

$$
\frac{\mathrm{d} F_{\mathrm{f}}}{\mathrm{d} z}=k s
$$

where $k$ is the stiffness parameter of the concrete-FRP interface. Based on the compatibility relation given in Equation 1, the equilibrium relation given in Equation 2 and the interface relation given in Equation 3, the following second-order differential equation is derived in terms of curvature

$$
\begin{aligned}
\frac{\mathrm{d}^{2} \chi}{\mathrm{d} z^{2}}-\alpha^{2} \chi & =-\frac{q}{E I_{\mathrm{c}}}-\alpha^{2} \frac{M}{E I_{\mathrm{tot}}}, \\
\alpha^{2} & =\frac{k}{E A^{*}} \frac{E I_{\text {tot }}}{E I_{\mathrm{c}}}
\end{aligned}
$$

where $E I_{\text {tot }}$ denotes the flexural stiffness of the MFFRP strengthened RC cross-section under the hypothesis of full composite action, which is defined as

$$
E I_{\text {tot }}=E I_{\mathrm{c}}+\frac{\left(E_{\mathrm{f}} A_{\mathrm{f}}\right)\left(E A_{\mathrm{c}}\right)}{E_{\mathrm{f}} A_{\mathrm{f}}+E A_{\mathrm{c}}} d_{\mathrm{f}}^{2}=E I_{\mathrm{c}}+E A^{*} d_{\mathrm{f}}^{2}
$$

where $E A_{\mathrm{c}}$ and $E_{\mathrm{f}} A_{\mathrm{f}}$ are the axial stiffness of the RC slab and FRP laminate cross-section, respectively; $q$ is the arbitrary transverse load distributed along the longitudinal axis of the beam; and $E A *$ denotes the effective axial stiffness of the MF-FRP strengthened RC section.

\section{Finite-element formulation of MF-FRP strengthened $R C$ beam element}

A two-node finite element can be formulated (Faella et al., 2002) by implementing the 'exact' solution in Equation 4 for the analysis of RC beams strengthened with MF-FRP laminates. In particular, the typical relation of flexibility-based finite elements can be derived for simply supported MF-FRP strengthened beam elements in the form

$$
\delta=D X+\delta_{0}
$$

where $X=\left[M_{i}, F_{i}, M_{j}, F_{j}\right]$ and $\delta=\left[\phi_{i}, s_{i}, \phi_{j}, s_{j}\right]$ are the vectors of nodal forces and nodal displacements, respectively, as illustrated in Figure 11(a). The

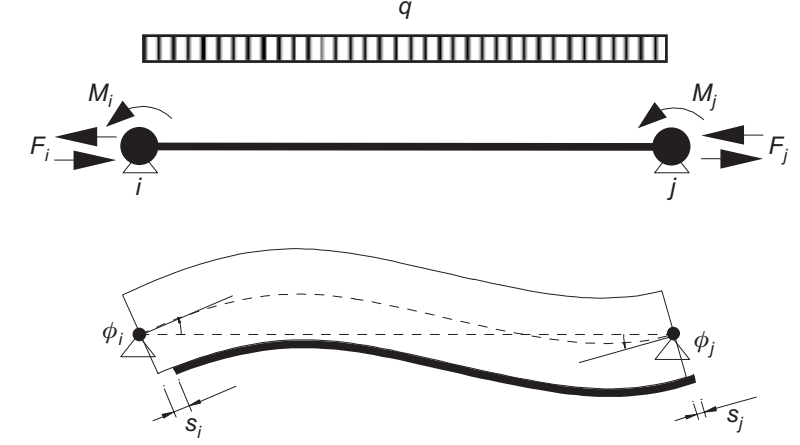

(a)
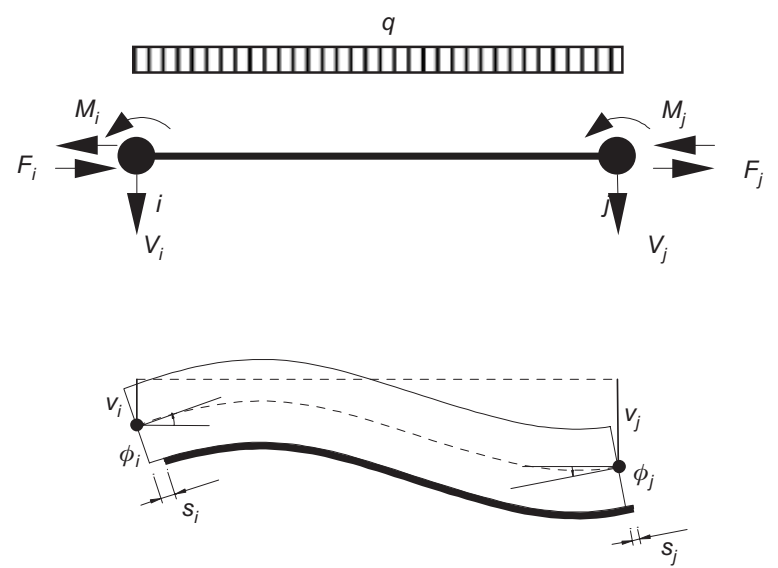

(b)

Figure 11. Nodal forces and displacements in two-node beam finite element: (a) simply supported beam for force-based element; (b) unrestrained beam for displacement-based element 
displacement-based relation that relates nodal forces and nodal displacements for an unrestrained MF-FRP strengthened beam, as shown in Figure 11(b), can also be obtained by inverting the flexibility matrix $D$. The relation between the vector of nodal forces, $Q=\left[V_{i}, M_{i}, F_{i}, V_{j}, M_{j}, F_{j}\right]$, and the vector of nodal displacements, $s=\left[v_{i}, \phi_{i}, s_{i}, v_{j}, \phi_{j}, s_{j}\right]$, is given as

$$
Q=K s+Q_{0}
$$

where $K$ is the stiffness matrix, and the vector $Q_{0}=\left[V_{\mathrm{o} i q}, M_{\mathrm{o} i q}, F_{\mathrm{o} i q}, V_{\mathrm{o} j q}, M_{\mathrm{o} j q}, F_{\mathrm{o} j q}\right]$ collects the nodal forces produced by the arbitrarily distributed load $q$.

\section{Non-linear analysis procedure}

The two-node finite element introduced can be used for non-linear analysis through fibre discretisation of the beam cross-section, and by implementing an iterative convergence procedure based on the 'secant' value approach to account for material non-linearity, including concrete, steel and concrete-FRP interface, as demonstrated earlier for the case of EB-FRP strengthened RC members (Faella et al., 2008). The original non-linear constitutive model for concrete (Faella et al., 2008) is assumed, whereas a modified bilinear stressstrain constitutive model for the steel rebars is adopted in the current paper, where strain-hardening is rendered by means of a constant modulus ratio of 0.03 between the elastic modulus in the plastic and the elastic range, respectively.

Since the assumption of conservation of plane sections was shown to be inaccurate, a suitable stress-slip model for the concrete-FRP interface must be defined and implemented in the numerical procedure. First, as the discrete connections are made by fasteners spaced at a longitudinal distance $i$ on-centre, the following approximation is introduced in Equation 3 for the longitudinal shear force per unit length

$$
\frac{\mathrm{d} F_{\mathrm{f}}}{\mathrm{d} z} \cong \frac{P(s)}{i}
$$

where $P(s)$ is the shear force transferred through a single fastener for the local value of slip, $s$, which is approximated as

$$
P(s)=k(s) s \cong \sigma_{\mathrm{f}}(s) t_{\mathrm{f}} d_{\mathrm{s}}
$$

where $k(s)$ is the non-linear stiffness parameter of the concrete-FRP interface, $\sigma_{\mathrm{f}}(s)$ is the bearing stress produced by the fastener in the FRP laminate, $t_{\mathrm{f}}$ is the thickness of the FRP laminate and $d_{\mathrm{s}}$ is the diameter of the fastener. The recently proposed bearing stress-slip $\left(\sigma_{\mathrm{f}}(s)-s\right)$ model shown in Figure 12(a) (Elsayed et al., 2009) is implemented, which is defined based on regression analysis performed on the results of shear tests on concrete blocks with FRP laminates connected by means of screw anchors

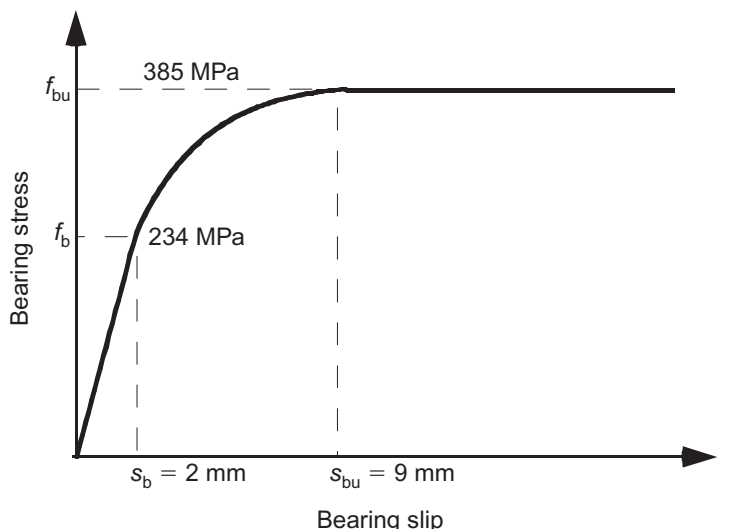

(a)

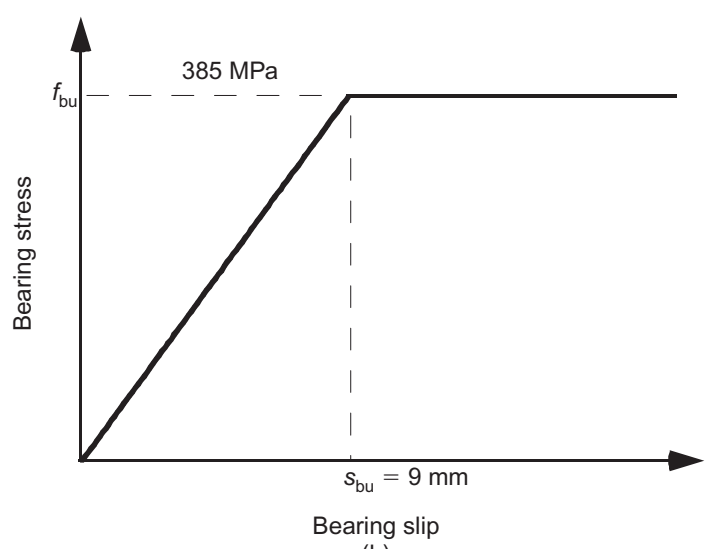

(b)

Figure 12. Modelling of bearing stress-slip: (a) accurate model for analysis; (b) simplified bilinear model for design

$$
\left\{\begin{array}{l}
\sigma_{\mathrm{f}}(s)=\frac{f_{\mathrm{b}} s}{s_{\mathrm{b}}} \quad \text { if } s \leqslant s_{b} \\
\sigma_{\mathrm{f}}(s)=f_{\mathrm{b}} A^{\exp \left(0.521 A^{0.50}\right)} \quad \text { if } s_{\mathrm{b}} \leqslant s \leqslant s_{\mathrm{bu}} \\
\sigma_{\mathrm{f}}(s)=f_{\mathrm{bu}} \quad \text { if } s \geqslant s_{\mathrm{bu}}
\end{array}\right.
$$

where $f_{b}=234 \mathrm{MPa}$ is the stress in the FRP laminate as bearing initiates, resulting in a deviation from linearity of the stress-slip relation, and $s_{\mathrm{b}}=2 \mathrm{~mm}$ is the associated slip; $f_{b u}=385 \mathrm{MPa}$ is the bearing strength of the FRP laminate, and $s_{\mathrm{bu}}=9 \mathrm{~mm}$ is the associated slip; and $A=s / s_{\mathrm{b}}$.

The bilinear $\sigma_{\mathrm{f}}(s)-s$ model shown in Figure 12(b) was also evaluated for use in design (for example, to define conservative design charts), where the more accurate non-linear model in Figure 12(a) was simplified in a conservative fashion by assuming a linear response up to $f_{\mathrm{bu}}-S_{\mathrm{bu}}$, and is rendered in the following form

$$
\left\{\begin{array}{l}
\sigma_{\mathrm{f}}(s)=\frac{f_{\mathrm{bu}} s}{s_{\mathrm{bu}}} \quad \text { if } s \leqslant s_{\mathrm{bu}} \\
\sigma_{\mathrm{f}}(s)=f_{\mathrm{bu}} \text { if } s \geqslant s_{\mathrm{bu}}
\end{array}\right.
$$

The following four failure mechanisms are accounted for as convergence is achieved in the proposed numerical procedure

Magazine of Concrete Research, 2010, 62, No. 8 
(a) concrete crushing, which occurs as the maximum strain in the concrete, $\varepsilon_{\mathrm{c}}$, computed in the extreme compression fibres, reaches its ultimate value, $\varepsilon_{\mathrm{cu}}=0 \cdot 004$

(b) yielding followed by rupture of the steel reinforcement, which occurs as the maximum steel tensile strain, $\varepsilon_{\mathrm{S}}$, reaches the rupture limit

(c) FRP tensile failure, which occurs as the longitudinal strain in the extreme tension fibre, $\varepsilon_{\mathrm{f}}$, reaches its ultimate value, $\varepsilon_{\mathrm{fu}}$, as defined in Table 1

(d) FRP bearing failure, which occurs as the maximum interface slip reaches a value of $20 \mathrm{~mm}$ in agreement with experimental measurements reported in the literature (Elsayed et al., 2009).

\section{Numerical results and discussion}

Representative comparisons between numerical and experimental mid-span vertical displacement curves with respect to the applied maximum bending moment for MF-FRP strengthened specimens are shown in Figure 13, including the results from both the bearing stress-slip models in Equation 10 (Elsayed et al., 2009) and Equation 11. Irrespective of the bearing-slip model implemented, crushing of the concrete was the predicted failure mode for all specimens, in agreement with the experimental results.

When the interface model in Equation 10 is implemented, the proposed numerical procedure yields moment-displacement curves in very good agreement with those measured experimentally for the case of pattern No. 1, irrespective of the FRP laminate length, as shown in Figures 13(a) and 13(b). As the fastener spacing is increased, as in pattern No. 2, the postcracking stiffness up to yielding of the steel reinforcement is approximated less accurately compared to pattern No. 1. A reasonable explanation may be found in the fact that such configuration results in greater shear forces carried by each fastener, which may produce a more extensive local cracking at the hole locations at relatively low loads, with consequent marginal reduction in the global flexural stiffness. In fact, a slightly smaller post-cracking stiffness could be measured when using pattern No. 2, as can be seen by comparing the experimental curves of specimens MF-1-L and MF-2-L in Figure 13. Still, very good results are obtained in terms of strength and displacement at failure. The range of theoretical maximum strain in the FRP laminate determined by way of Equation 10 and Equation 11 is generally in fair agreement with the experimental measurements, as summarised in Table 4. In all cases, the use of the interface model in Equation 11 leads to more conservative strength results, consistent with its purpose. Therefore, the model in Equation 11 may be implemented in the proposed numerical procedure to evaluate design alternatives.

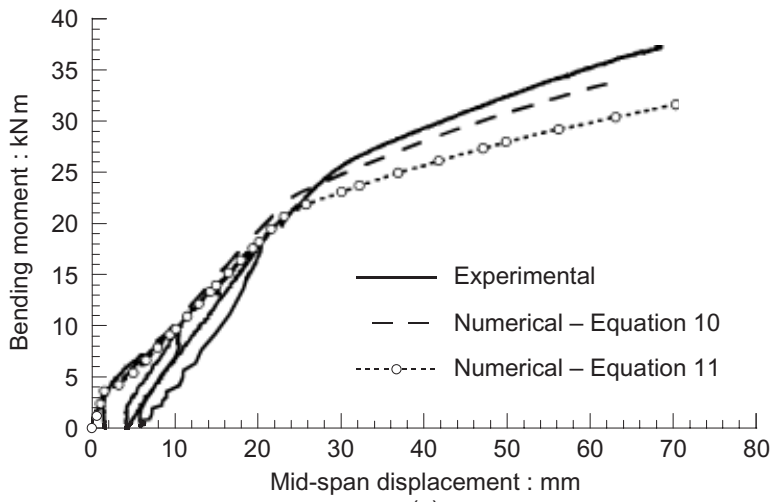

(a)

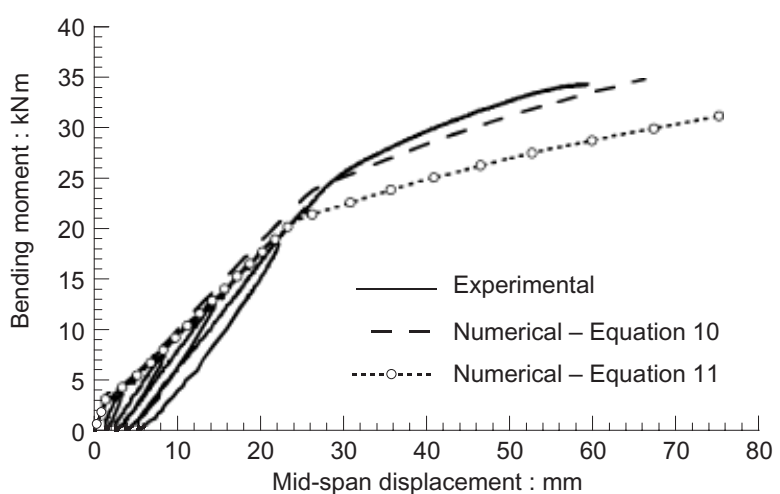

(b)

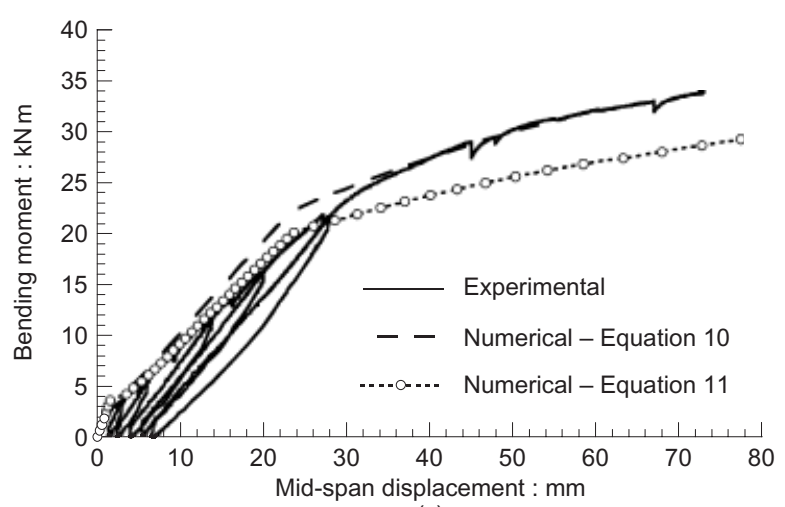

(c)

Figure 13. Comparison of experimental and numerical bending moment-mid-span displacement curves for representative $M F-F R P$ specimens: (a) $M F-1-L$; (b) $M F-1-S$; (c) $M F-2-L$

Table 4. Experimental and numerical maximum longitudinal FRP strain at failure

\begin{tabular}{l|c|c|c}
\hline \multirow{2}{*}{ Specimen ID } & \multicolumn{3}{|c}{$\varepsilon_{\mathrm{f}}: \%$} \\
\cline { 2 - 4 } & Experimental & $\begin{array}{c}\text { Numerical, } \\
\text { Equation 10 }\end{array}$ & $\begin{array}{c}\text { Numerical, } \\
\text { Equation 11 }\end{array}$ \\
\hline MF-1-L & 0.65 & 0.66 & 0.52 \\
MF-1-S & 0.41 & 0.66 & 0.49 \\
MF-2-L & 0.41 & 0.49 & 0.40 \\
MF-2-S & 0.46 & 0.41 & 0.37 \\
\hline
\end{tabular}




\section{Summary and conclusions}

An experimental and numerical study has been presented aimed at better understanding the effect of alternative configurations of MF-FRP strengthening systems on the flexural response of RC slabs, as well as the influence of differential deformations at the concrete-FRP interface mainly accruing from bearing of the fasteners on to the FRP laminate. Six RC slab specimens were tested to failure in four-point bending; the specimens included a benchmark unstrengthened slab, a slab strengthened by means of an externally bonded carbon FRP laminate installed by way of wet lay-up, and four MF-FRP strengthened specimens with two different laminate length and fastener patterns. All the FRP strengthened slabs were designed to attain a similar ultimate strength. From the experimental study, the following conclusions are drawn.

(a) An increase in the yielding moment of the MFFRP strengthened slabs was measured up to $26.6 \%$, with decreases in maximum displacement limited to less than $2 \%$ compared to the unstrengthened specimen.

(b) An increase in the ultimate moment of the MFFRP strengthened slabs was measured up to $58.7 \%$, comparable with that of the EB-FRP strengthened slab. A reduction in mid-span displacement up to $36 \cdot 1 \%$ was also observed, where smaller displacements were measured when using a denser fastener pattern (pattern No. 1 in Figure $3(\mathrm{a}))$.

(c) Enhanced deformability at ultimate was attained using MF-FRP laminates with the less dense fastener pattern (pattern No. 2 in Figure 3(b)), since the smaller number of fasteners per unit length promoted the development of the bearing-slip mechanism at the concrete-FRP interface.

(d) The longitudinal FRP strain profile in the MF-FRP strengthened slabs is fairly linear and symmetric at all load levels, which is indicative of an even load transfer among the fasteners. The peak strain at similar load levels is greater when using less dense fastener patterns owing to the further development of the bearing-slip mechanism.

(e) The bearing-slip that develops at the FRPconcrete interface should not be neglected. Relying on the common hypothesis of conservation of plane sections may lead to inaccurate predictions.

The numerical study presented had the objective of developing and verifying rational and suitable procedures for analysis and for design, where the former implements an accurate constitutive model of the interface bearing stress-slip into a non-linear two-node beam element, whereas the latter implements a simplified, conservative constitutive model. The proposed procedure yields predictions that are in good agreement with the experimental results when using the accurate non-linear interface bearing-slip model. Reasonably conservative results are obtained when using the simplified (bilinear) model, making it suitable for design purposes.

\section{Acknowledgements}

The project reported in this paper was supported by the National Science Foundation Industry/University Cooperative Research Center for 'Repair of buildings and bridges with composites' $\left(\mathrm{RB}^{2} \mathrm{C}\right)$. Strongwell Corporation, industry member of $\mathrm{RB}^{2} \mathrm{C}$, donated the prefabricated FRP laminates used in the experiments. These contributions are gratefully acknowledged.

\section{References}

ACI (American Concrete Institute) (2008) Guide for the Design and Construction of Externally Bonded FRP Systems for Strengthening Concrete Structures. ACI Committee 440, American Concrete Institute, Farmington Hills, Michigan, ACI 440.2R-08.

Arora D (2003) Rapid Strengthening of Reinforced Concrete Bridge with Mechanically Fastened Fiber-Reinforced Polymer Strips. MSc thesis, University of Wisconsin-Madison, USA.

Ascione L, Napoli A, Realfonzo R, Matta F and Nanni A (2009) Strengthening of masonry with mechanically fastened FRP laminates. Proceedings of the 3rd National Congress on Mechanics of Masonry Structures Strengthened with Composite Materials - Modeling, Testing, Design, Control, Venice, Italy, CD-ROM \#MEM-27-4.

ASTM (American Society for Testing and Materials) (2009) Standard test method for compressive strength of cylindrical concrete specimens. ASTM, West Conshohocken, PA, ASTM C39/C39M-09.

Bank LC and Arora D (2007) Analysis of RC beams strengthened with mechanically fastened FRP (MF-FRP) strips. Composite Structures 79(2): 180-191.

Bank LC, Oliva MG, Arora D and Borowicz DT (2003) Rapid Strengthening of Reinforced Concrete Bridges. Wisconsin Highway Research Program, USA, Report WHRP 03-06.

BASF (2008) MBrace ${ }^{\mathbb{B}}$ CF130 - Unidirectional high strength carbon fiber fabric for the MBrace ${ }^{\mathbb{B}}$ composite strengthening system. See http://www.buildingsystems.basf.com/documents/z30_tdg.pdf for further details (accessed 13 May 2010).

Camanho PP and Matthews FL (1997) Stress analysis and strength prediction of mechanically fastened joints in FRP: a review. Composites Part A 28(6): 529-547.

De Lorenzis L and Teng JG (2007) Near surface mounted FRP reinforcement: an emerging technique for strengthening structures. Composites Part B 38(2): 119-143.

Dempsey DD and Scott DW (2006) Wood members strengthened with mechanically fastened FRP strips. Journal of Composites for Construction 10(5): 392-398.

Ekenel M, Rizzo A, Myers JJ and Nanni A (2006) Flexural fatigue behavior of reinforced concrete beams strengthened with FRP fabric and precured laminate systems. Journal of Composites for Construction 10(5): 433-442.

Elsayed WE, Ebead UA and Neale KW (2009) Studies on mechanically fastened fiber-reinforced polymer strengthening system. $A C I$ Structural Journal 106(1): 49-59.

Faella C, Martinelli E and Nigro E (2002) Steel and concrete composite beams with flexible shear connection: 'exact' analytical expression of the stiffness matrix and applications. Computers and Structures 80(11): 1001-1109.

Faella C, Martinelli E and Nigro E (2008) Formulation and validation 
of a theoretical model for intermediate debonding in FRP-strengthened RC beams. Composites: Part B 39(4): 645-655.

Hassan NK, Mohamedien MA and Rizkalla SH (1997a) Multibolted joints for GFRP structural members. Journal of Composites for Construction 1(1): 3-9.

Hassan NK, Mohamedien MA and Rizkalla SH (1997b) Rational model for multibolted connections for GFRP members. Journal of Composites for Construction 2(1): 71-78.

Lamanna AJ (2002) Flexural Strengthening of Reinforced Concrete Beams with Mechanically Fastened Fiber Reinforced Polymer Strips. PhD thesis, University of Wisconsin-Madison, USA.

Lamanna AJ, Bank LC and Scott DW (2001) Flexural strengthening of reinforced concrete beams using fasteners and fiber reinforced polymer strips. ACI Structural Journal 98(3): 368-376.

Lamanna AJ, Bank LC and Scott DW (2004a) Flexural strengthening of reinforced concrete beams by mechanically attaching fiber-reinforced polymer strips. Journal of Composites for Construction 8(3): 203-210.

Lamanna AJ, Bank LC and Borowicz DT (2004b) Mechanically fastened FRP strengthening of large scale RC bridge $\mathrm{T}$ beams. Advances in Structural Engineering 7(6): 525-538.

Martin JA and Lamanna AJ (2008) Performance of mechanically fastened FRP strengthened concrete beams in flexure. Journal of Composites for Construction 12(3): 257-265.

Napoli A (2008) RC Structures Strengthened with Mechanically Fas- tened FRP Systems. MSc thesis, University of Miami, Florida, USA.

Newmark NM, Siess CP and Viest IM (1951) Tests and analysis of composite beams with incomplete interaction. Proceedings of the Society of Experimental Stress Analysis 9(1): 75-92.

Powers Fasteners (2008) Powers wedge bolt specification and design manual. Powers Mechanical Anchors and Fasteners Catalogue, pp. 67-83. See http://www.powers.com/pdfs/catalogs/00017 mechanical_section.pdf for further details (accessed 13 May 2010).

Quattlebaum JB, Harries KA and Petrou MF (2005) Comparison of three flexural retrofit systems under monotonic and fatigue loads. Journal of Bridge Engineering 10(6): 731-740.

Rizzo A (2005) Application of Mechanically Fastened FRP (MFFRP) Pre-cured Laminates in Off- System Bridges. MSc thesis, University of Missouri-Rolla, USA.

Rosner CN and Rizkalla SH (1995) Bolted connections for fiber reinforced composite structural members: experimental program. Journal of Materials in Civil Engineering 7(4): 223-231.

Strongwell (2009) http://www.strongwell.com (accessed 1/04/2009).

Teng JG, Chen JF, Smith ST and Lam L (eds) (2002) FRP-Strengthened RC Structures. Wiley, Chichester, UK.

Discussion contributions on this paper should reach the editor by 1 February 2011 